\title{
\#26
}

\section{SOMA POÉTICA. FORMAS Y MATERIAS DEL CUIDADO CON VICENTE LUYY HERNÁN}

Francisco Gelman Constantin

Universidad de Buenos Aires - Instituto de Literatura Hispanoamericana / Conicet

https://orcid.org/0000-0003-2478-0892

Ilustración || ๑ Pedro Rodríguez Expósito a.k.a p.strange - Todos los derechos reservados

Texto || ( Francisco Gelman Constantin - Licencia: Atribución-NoComercial-SinDerivadas 4.0 Internacional de Creative Commons

\section{(c) (i) (3) $\Theta$}




\section{$452^{\circ} \mathrm{F}$}

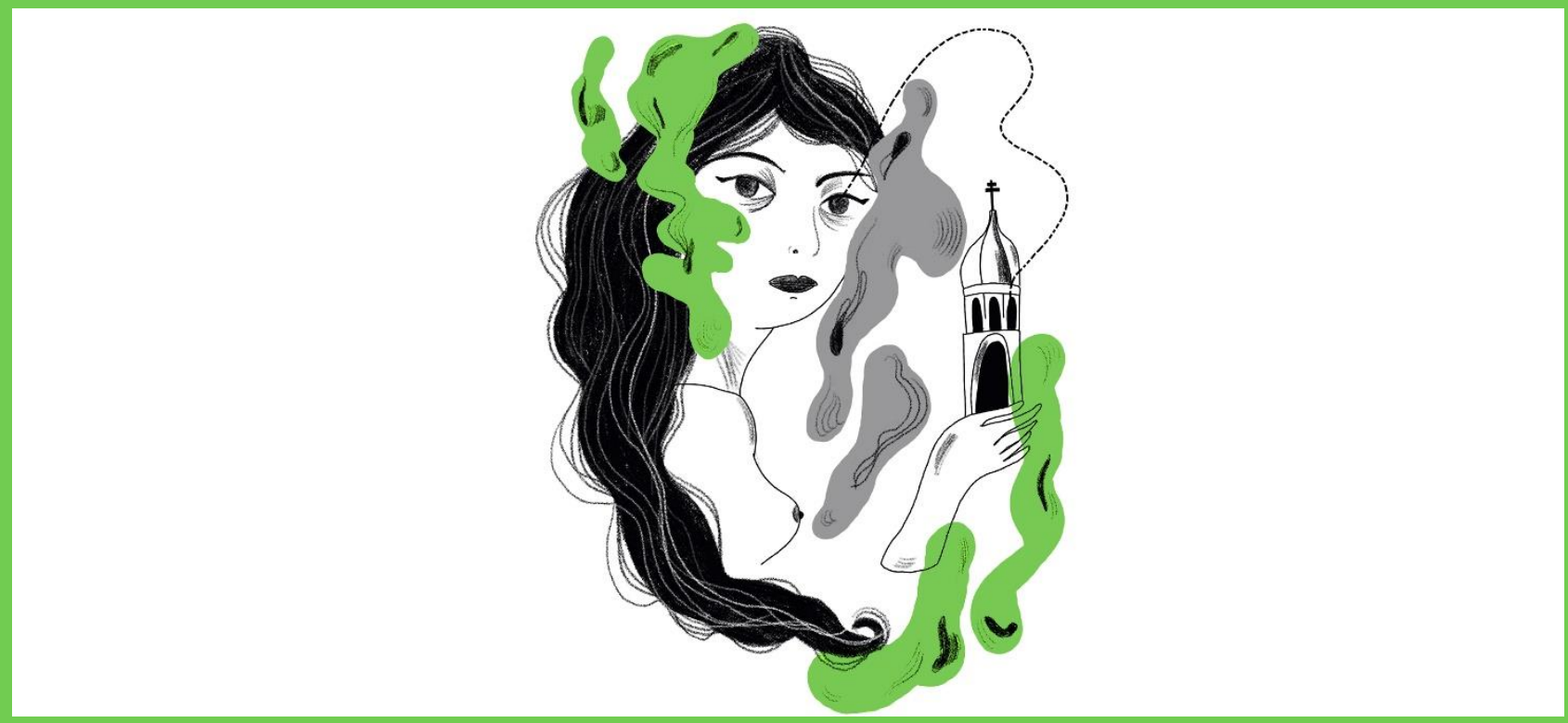

Resumen || A partir de La poesía está en ser uno. Los libros de Vicente Luy, de Hernán, el artículo propone una relectura de la obra de Luy y una reversión de las teorías sobre la relación entre obra y vida que surgiría de su poética. El protagonismo del padecimiento y las redes de cuidado en esas escrituras permitiría revisitar los vínculos entre forma y materia alrededor de las discusiones entre autonomía literaria o estética, y expansión o posautonomía. Lejos del inmanentismo y la especificidad, la forma de la poesía en los libros firmados por Luy coincidiría con aquellos procedimientos que hacen aparecer las materialidades que constituyen sus condiciones de posibilidad, incluido el «complejo autoral» a varias manos que está «detrás» de los libros.

\section{Palabras clave || Poesía | Cuidado | Forma | Materia | Autonomía | Posautonomía}

Abstract || From a reading of La poesía está en ser uno mismo. Los libros de Vicente Luy, by Hernán, this paper proposes a re-reading of Luy's work and a new version of the theories about the relationship between work and life that would emerge from his poetics. The protagonism of suffering and care networks in these writings allow for the revisiting of the links between form and matter around the discussions between literary or aesthetic autonomy, and expansion or post-autonomy. Far from immanentism and specificity, the form of poetry in the books authored by Luy would coincide with those procedures that make the materialities that constitute their conditions of possibility appear, including the multi-handed «author complex» «behind» the books.

\section{Keywords || Poetry | Care | Form | Matter | Autonomy | Postautonomy}

Resum || Partint de La poesía está en ser uno mismo. Los libros de Vicente Luy, de Hernán, l'article proposa una relectura de l'obra de Luy i una reversió de les teories sobre la relació entre obra i vida que sorgiria de la seva poètica. El protagonisme del patiment i de les xarxes de cures en aquestes escriptures permetria revisitar els vincles entre forma i matèria al voltant de les discussions entre autonomia literària o estètica, i expansió o posautonomia. Lluny de l' immanentisme i l'especificitat, la forma de la poesia en els Ilibres firmats per Luy coincidiria amb aquells procediments que fan aparèixer les materialitats que constitueixen les seves condicions de possibilitat, inclòs el «complex autorial» a diverses mans que està «darrere» dels llibres.

Paraules clau || Poesia | Cures | Forma | Matèria | Autonomia | Posautonomia 


\section{Introducción ¿anecdótica?}

Centro Cultural «El mismo latir», Hospital Borda, Buenos Aires, noviembre de 2010. Hernán —instigador externo-, Vicente Luy —entusiasta internoy una cantidad de otros pacientes y visitantes desarrollan una nueva edición del ciclo «Poemas y canciones», trasladado por primera vez al interior de un hospital psiquiátrico ${ }^{1}$. Se lee, se canta, se conversa, se escucha. No es la primera vez que Hernán se reúne con Luy dentro de esas paredes, pero es la primera que dejan un rastro tan fácil de recuperar, una jornada que sobrevive en las fotos de Alejandro Pi-Hué y en los relatos de varios (Hernán, 2020: 213; entre otros). Se ve una cantidad de gestos, alguna sonrisa, alguna mirada enfática; probablemente Luy leyera alguno de los poemas que luego compondrían Plan de operaciones, el libro que estaba preparando con la ayuda de Hernán, a lo largo incluso de las visitas anteriores en el Borda. No consta si osó mencionar, como lo hace en el texto "Te había contado que a veces...», los electroshocks que seguramente estarían ocurriendo algunos pasillos más allá.

Comenzar por este recuadro podría parecer una introducción anecdótica, pero importa admitir - siquiera como condescendencia preliminar a lo que sigue-que acaso no lo sea. Estas primeras líneas del artículo reescriben un pasaje de La poesía está en ser uno. Los libros de Vicente Luy, que el poeta porteño Hernán publicó en 2020, y lo engordan a partir de algunas referencias dispersas e imágenes que pueden encontrarse en internet y en su propio sitio web (Trenes hacia afuera). La lectura de ese libro es el punto de partida de la relectura de la poesía de Luy que conduce este texto. Y de lo que se tratará a lo largo del artículo será de argumentar hasta qué punto y de qué modo es necesario hacerle lugar a esa escena por la que comenzábamos, incluso en sus elipsis, incluso en sus incertidumbres, incluso sin saber cómo; se tratará de investigar hasta qué punto y de qué modo leer a Luy de la mano de Hernán requiere comprender la relación de la escritura con materialidades que la exceden como un momento intrínseco de las operaciones de los estudios literarios. A través de un recorrido irregular por unos treinta años de su poesía, se tratará de explorar qué tipo de hipótesis sobre las relaciones entre la materialidad del dolor y el cuidado, y su puesta en forma en la escritura pueden hacer justicia a ese obrar.

Si el obrar es cada vez más indisociable de una teorización adyacente o de cierta poética autoral que vienen en gran medida a reemplazar a la teoría estética (Groys, 2014 y 2020), con Luy y Hernán perseguimos una teorización o una poética imposible de diferenciar con claridad de la obra misma, que desafía algunos modos habituales de comprender la teoría y que excede la autoría individual, para ampliarse en un complejo autoral que incluye las materialidades del cuidado que hacen posible la autoría; ese entrecuerpos-artefactos-imágenes-tejes que es condición de la escritura avanza al frente de la escena y reclama su lugar en la teoría. 


\title{
1. Soportar, encuadrar, colgar: versiones de la relación obra-vida
}

Luy declara una y otra vez leer poco, pero entre el puñado de autores que dice haber transitado con gusto, hojas venidas a él como una pieza más entre una generosa herencia, está ese amigo de su abuelo también poeta Juan Larrea, que fue César Vallejo. Acaso se justifique así tomar como incitación inaugural para este artículo algunos versos del poeta peruano, allí cuando escribe:

\author{
Un pilar soportando consuelos, \\ pilar otro, \\ pilar en duplicado, pilaroso \\ y como nieto de una puerta oscura. \\ Ruido perdido, el uno, oyendo, al borde del cansancio; \\ bebiendo, el otro, dos a dos, con asas. \\ ¿lgnoro acaso el año de este día, \\ el odio de este amor, las tablas de esta frente? \\ ¿lgnoro que esta tarde cuesta días? \\ ¿lgnoro que jamás se dice «nunca», de rodillas? [...] \\ Consolado en terceras nupcias, \\ pálido, nacido, \\ voy a cerrar mi pila bautismal, esta vidriera, \\ este susto con tetas, \\ este dedo en capilla, \\ corazónmente unido a mi esqueleto (2013: 297).
}

Hay toda una serie espacial, arquitectónica, en las teorías modernas sobre las relaciones entre obra y vida —cuyo ejemplo más obvio son los alegatos contra la torre de marfil- que podemos prolongar hasta este poema de Vallejo. Para un pensamiento sobre esas relaciones que sostenga un vínculo no vertical con el obrar poético, esas imágenes verbales espacializadoras no son materia bruta que haya que bruñir hasta extraer el núcleo conceptual del que serían una metáfora accesoria; prolongando los argumentos de Silvia Rivera Cusicanqui sobre las imágenes a secas (2015), se trata más bien de reconocer en esas figuras un momento inevitable de cierto modo de pensar no jerárquico. Fantasmas insidiosos a la teoricidad del pensamiento (Lacan, 2004), esas arquitectónicas espacializan lo que se querría enteramente algebraico, como si las formas fueran reductibles a una geometría analítica ${ }^{2}$.

En el poema de Vallejo, la figura del cuerpo de los padres como pilares que se prolongan hasta el cuerpo propio y soportan la materialidad presente que signa la inscripción escrituraria de «esta tarde», haciéndola posible, pero que la escritura empuja hacia el cierre, exhibe una lógica del sostén como condición de posibilidad que busca ponerse en evidencia. Son precisas esas modalidades del cuidado que son el consuelo y la escucha para que pueda emerger la poesía. De lo que se trata en el poema es precisamente de mencionar a esos pilares, de subrayar el movimiento en que se retiran antes de que desaparezcan, pero hay algo en la figura misma del pilar que parece dejar apuntada la imposibilidad: un pilar está siempre por debajo, retrocediendo de la mirada. 
$Y$, sin embargo, esa subordinación del sustrato somático de la escritura que lo deja fuera de escena, lejos de ser una necesidad apriorística, es un producto del proceso de autonomización estética. Es que las fronteras que separan a la obra de sus condiciones materiales de posibilidad y de sus conexiones actuales o potenciales con mundos de vida son el efecto de un modo de leer. Es fácil recordar el relato policial con el que comienza la teoría literaria: ante unos «historiadores literarios» que operan como «un policía que, proponiéndose detener a alguien, hubiera echado mano, al azar, de todo lo que encontró en la habitación y aun de la gente que pasaba por la calle vecina» (Jakobson citado en Eichenbaum, 2004: 26), el deber de la ciencia literaria es ser el detective astuto que se atenga a las pruebas fehacientes, a la sustancia formal del texto, dejando fuera, detrás de la puerta, el resto.

Ese exterior incierto producto de la clausura epistemológica autonomista hacia el interior del texto no solo surge de un deber de método, sino que surge de un deber político, según ha argumentado Martín Kohan: «si la praxis social dominante no da motivos de encomio, o hasta puede merecer repudio, la liquidación de la autonomía del arte no serviría sino para evidenciar su profunda necesidad, es decir para echarla de menos»; así pues, «las propias obras [d]espojadas de su tensión autónoma, o deshaciéndose de ella por alguna razón, han de quedar fatalmente neutralizadas y dócilmente integradas al imperio de lo existente. La autonomía es su única opción de resistencia» (2013: 312, 316). Para los defensores contemporáneos de la autonomía, el cierre de las obras sobre sí mismas es el último reducto posible para su acción crítica sobre una realidad circundante de la que se excluyen, como si fuera de la «praxis dominante» sólo estuvieran ellas. Lejos de la torre de marfil y bajo la forma paradójica de la mónada leibniziana, en teorías sociales de la autonomía como estas la interiorización es condición de posibilidad de una relación representativa con la totalidad social, con la que entabla un vínculo crítico en términos de negatividad; pero, en esa precisa medida, cualquier dimensión presentativa del vínculo de la obra con sus condiciones materiales inmediatas de (re)producción -su «nexo efectual»- es apartada del interés como una regresión ideológica y una concesión al orden imperante que acaba por resultar unívoco (Adorno, 2014: 120, 138). Puesto que todo lo demás que vive y trabaja a su alrededor sería solidario del horror, bajo supuesto de la «universal mediación», su salvación depende de que «las obras de arte [...] no tengan propósitos útiles para la autoconservación y la vida», según sentenciaba Adorno (1962: 129; 2014 : 205). Aunque se argumenta que «la dialéctica negativa en Adorno permite superar la dicotomía adentro / afuera», la «separación» insiste bajo la figura de «los textos mismos [como] un espacio protegido de las injerencias» (Kohan, 2013: 316, 317), definición irreductible de la interioridad, que la mediación dialéctica acaba subrayando para sostener apenas la relación entre totalidad estética de la obra y totalidad social, reacia a cualquier proximidad concreta efectiva o posible que cae bajo sospechas simétricas de utilitarismo o psicologismo. Si la relación dialéctica entre la mónada y el mundo no supone su aislamiento respectivo y no coincide con el inmanentismo de ciertos «formalismos», sí da una forma muy específica a la oposición entre obra y vida colectiva que solo puede ocurrir en presencia de ciertos límites específicos y como relación de todo a todo. 
Bastante lejos de Adorno y Kohan, en su ensayo «El arte de vivir en arte», Alan Pauls seguía el recorrido de varios autores latinoamericanos del último tiempo en conversación con el arte-objeto, el arte conceptual y las performances, y se preguntaba « ¿hasta qué punto los textos pueden existir sin la presencia del autor?» (2014: 176). ¿Qué vínculo tienen las condiciones y tránsitos vitales con la escritura más allá del mero prólogo biográfico pero más acá de la explicación biografista? Pauls proponía recorrer el archivo continental contemporáneo pensando «la relación entre literatura y vida» como "un modo de hacer, [...] un conjunto de reglas, instrumentos y protocolos que definen un tipo de experiencia específica, transforman una materia y producen efectos en un campo de fuerzas determinado», "puesta en forma y en acción» que supone una "crítica de la autonomía de la literatura» (2014: 171, 173, 179). Contra aquellas posiciones que implican una tarea de «delimitar y repartir los territorios y las economías de la vida y de la obra», el «puro interior» del texto respecto de su «exterior», el "despliegue» vital no sabe de esas fronteras (2014: $172,173)$. En las «anécdotas» revistadas a lo largo del ensayo «la vida parece ser el material del que están hechos y el soporte en el que se inscriben. Pero en rigor son biografemas; es decir: bloquecitos de vida ya encuadrados, escenificados» (2014: 73-174). Así, los procedimientos de encuadramiento o puesta en escena que posicionan lo escrito en un marco diverso y compuesto, lejos de surgir de un imperativo metódico previo, aparecen como parte del problema, poniendo en cuestión las hipótesis de exterioridad/interioridad ${ }^{3}$.

Compañera de ruta de Pauls en la expansión de la literatura, Natalia Brizuela la busca «fuera de sí» allí donde coincide con la fotografía en ciertos gestos de desfondamiento de la especificidad y hasta la «"prosa de la vida"» (2014: 16). Ese desfondamiento no equivale a ningún presunto despojamiento documental, como si no hubiera operaciones de «encuadre» determinantes en cualquiera de esos procedimientos; como deslizó Judith Butler (2010: 51), «marco» y «forma» son en muchos casos términos intercambiables. Interesantemente, en Depois da fotografía, Brizuela retoma también los adornianismos latinoamericanos de nuestros días y el modo en que insisten en la cohesión transhistórica de un arte «dentro de sí», tensionado por pero siempre diferente de aquella realidad externa que «no es», ante la que opone un límite (Brizuela, 2014: 87). Contra ellos, Brizuela ensaya lecturas de Adorno a contrapelo, por sobre su propia interioridad argumental, y explora «los límites del libro» en un movimiento de «asalto de espacios» que coincide con la dispersión de la autoidentidad y la constitución de «espacios indecisos» (2014: 141 y ss.).

Aunque indisimuladamente vuelto hacia al costado adorniano ${ }^{4}$, Fernando Bogado ha visto bien el modo en que la poesía de Luy interroga los modos de leer alrededor de la fractura entre autonomistas y posautonomistas, y propone una confrontación entre su poesía y el Aquí América Latina en el que Josefina Ludmer (2010) se dedicaba a las «literaturas posautónomas». De acuerdo con Bogado, la óptica de Ludmer impone sobre la poesía su ley autoritaria como crítica y desdiferencia las singularidades enunciativas, mientras que la poesía de Luy avanzaría en el resguardo del lugar del interlocutor como diferencia irreductible y propiamente literaria. Pero, al 
mismo tiempo, la «poesía [...] rastrera y de cabotaje» de Luy (Luy en Hernán, 2020: 172) parece bastante dispuesta a esa ausencia de mediaciones y fronteras que sugiere Ludmer, lista para actuar más allá de los límites de la institución literaria (Bogado, 2019: 123-124). El subrayado de Bogado sobre la expresión de Luy, una poesía que se rehúsa a volar alto por encima de las guerras de la vida, coloca a la escritura en uno de los lados en contienda vital, en lugar de oponerla a la vida misma como un todo (con su lógica «dominante»); táctica y posicional, nunca sobrepuesta, la espacialidad de Luy quiebra lanzas contra la sinóptica.

Arriba y abajo, adentro y afuera, adelante y atrás, cada una de las arquitectónicas alrededor del modo de inscripción de lo poético o literario dentro del territorio amplio de la vida social implica lógicas de poder, de visibilidad y de causalidad. Enfrentado a la topología autonomista y más cerca entonces de Ludmer, Pauls y Brizuela, el plan de la poesía de Luy va «bajo la superficie» (2012: 49), no en busca de una profundidad determinante (psicológica, espiritual) sino de la manera de reconstruir los estratos múltiples y en movimiento que conforman la arquitectónica vital en la que se inscriben las palabras. Persigue un juego entre superficies múltiples, entre pasadizos y puertas abiertas, tal que la vida, el cuerpo de la escritura, no pueda ya más ser un pilar a oscuras que soporte a la letra, un exterior al que se le cierre la puerta.

La maniobra de inversión se hace obvia allí donde más suenan los ecos del poema de Vallejo, en un texto de La vida en Córdoba: «deme más café, dijo mi mamá, totalmente borracha. Yo estaba en brazos de su marido, y me enamoré al instante. Después se fueron al cielo y todavía no bajan. Tienen mi corazón. De ahí cuelgo.» (Luy, 2020: 42). La causa genealógica ya no funciona como un pilar ensombrecido, sino que desde ella se cuelga, pendiendo como en Vallejo por el corazón, que aquí empero conserva el latido, pero pierde la latencia. Más que apoyarse sobre la vida, el poema podría entonces colgar de ella (es un pendiente, es un ahorcado, es una plomada, es un ancla), de tal modo que es imposible pensar su posición sin incluir en el campo visual, en el campo de lectura y experimentación, aquello de lo que cuelga, ese cuerpo vivo intergeneracional que lo hace posible. Como ese cuerpo plural mismo, las imágenes no son aquí accesorias.

La versión inicial de esa topología singular que produce la escritura de Luy para las relaciones entre arte y vida aparece en el primer libro, Caricatura de un enfermo de amor. A diferencia de lo que veremos luego sobre sus libros posteriores, Caricatura es un texto en que la forma todavía es concebida como oclusión e impedimento: el uso del «vosotros» y el «tú», la hipótesis del estilo, la propuesta del yo como totalidad resuenan como dimensiones problemáticas pero irreductibles. Con todo, Caricatura agrupa los «libritos» que componía Luy por temporadas durante su juventud y cada uno (o a veces incluso cada poema) entra al libro con su propia fecha y una inscripción topográfica: el nombre de un barrio, un hospital o un cuartel. Esas inscripciones en los umbrales de los poemas sugieren la negociación de los bordes, hacia el desborde, un ademán «frente a la pared, estudiando sus poros» pero todavía sin atravesarla, incluso si la pared «se mueve» (2018: 43, 47). En una búsqueda afanosa de puertas y ventanas que abrir, 
sobre las limitaciones formales, sobre las paredes, Caricatura se sitúa como una promesa, con la constatación de que es imposible borrarse en la inmanencia de la obra, que siempre dejará «rastro», una «energía» que excede al «proyecto» en el que se emplee, un excedente de vitalidad que sobrepasa cualquier efecto limitante de la forma (2018: 83).

\section{Formas del cuidado, materias de la escritura}

Si para Kohan (2020), a diferencia de la performance corpórea propia de la ejecución musical, la literatura se caracterizaría por el acto no de «poner el cuerpo» sino el de «hurtarlo», de expulsarlo del objeto que se comparte socialmente, el modo de leer a Luy en las huellas de Hernán que seguimos aquí propone una resomatización activa de la escritura, incluso si pone en peligro el modo de circulación de la palabra literaria instituido por una parte de los estudios literarios académicos.

No pasa por un capricho anecdótico que un crítico presente el libro póstumo de Luy recordando al poeta como «huésped de neuropsiquiátricos, carne de electroshocks, medicado al extremo, rotulado de bipolar, o simplemente como portador de un trastorno obsesivo compulsivo» (Grinberg, 2013: s/p): todos esos predicados ingresan a la reflexión sobre la obra para pensar su sustancia y sus usos, no como una pura imposición biografista sino como efecto del horadamiento que imprimen los propios procedimientos de la escritura.

Volvamos otro momento a Adorno para comprender lo que perseguimos en Luy. La hipótesis adorniana es que la cerrazón autonómica (1962: 132) es aquello que permite enfrentar la obra a la violencia del capitalismo, de modo que la clausura relativa de la forma estética es la única salvación ante el carácter autoritario de las formas de la vida social y aquello que permite criticarlas de manera objetiva:

Esas formas de la existencia exterior son las determinantes del dominio de la naturaleza, y en el arte están a su vez dominadas, de ellas se dispone libremente. Mediante la dominación de lo dominador, el arte revisa interiormente el dominio de la naturaleza (Adorno, 2014: 187).

Esa hipótesis paradójica de la «dominación de lo dominador» es el modo en el que Adorno busca dar cuenta de la capacidad de la forma estética de actuar sobre la materia con «ausencia de violencia», de «socorrer a lo no idéntico que es oprimido en la realidad» $(2014: 18,13)$. No obstante, parece difícil de justificar por qué esa posible facultad de socorro toma a la autonomía por «irrevocable», por qué hace falta replicar la dominación para domeñarla en ese gesto soberano que es la separación autonomista «que hace cortes en lo vivo para hacerle hablar» (2014: 9, 194-195). Si, en efecto, el arte debe responder del «sufrimiento» allí donde el «conocimiento discursivo» fracasa (2014: 32-33), no hay ninguna garantía de que esa tarea dependa de la autoexclusión, no es evidente por qué ese socorro debería para siempre preservar la separación de la esfera del arte (o de la poesía en particular). 
Inversamente, podemos ver el obrar de Luy, Hernán, María Angélica Vaca Narvaja y otros y otras en «sus» libros como una estrategia en la que la acción de la forma escrituraria sobre la materia somática más-queindividual coincide con la apertura del espacio en el que emerjan los lazos intrínsecos entre esa escritura y todo el entretejido material que la hace posible y con el que interactúa, lejos de la diéresis autonómica. Y eso precisamente porque responde a la misma necesidad de una forma que no opere con violencia sobre aquello que informa, sobre la materia corporal en la que actúa, tanto la del complejo autoral como la de quienes lean u oigan. Una escritura que trata el padecer (el dolor, el miedo) no tolera que para la carne la escritura sea pura pasión obnubilante, puro padecimiento del cuerpo bajo la rección de la letra. No una escritura en la que se trata del padecer (no es simplemente un «tema», según la expresión de Hernán; 2020: 28) dejándolo en la condición pasiva y acalladora de objeto, sino una escritura que lo trata, que actúa, terapéuticamente, informándolo; y que lo hace sin sujetarlo a su autoridad, o a su autoría —el dolor nunca puede, completamente, ser firmado-, sino reorganizando su materialidad y dejando que aparezcan propiedades suyas que estaban fuera de cuadro.

Esa exploración comenzaba ya en Caricatura, que entre esa forma más onerosa, más oclusiva que identificábamos, llegaba sin embargo a advertir sobre su propio carácter impositivo: en poesía, «un enfermo empieza con "i", o no/ la rima lo determina» (Luy, 2018: 27). Esa fuerza de «determinación» de ciertas formas, su capacidad de imponer una naturaleza sobre el cuerpo sufriente del enfermo, es el objeto de un progresivo trabajo de zapa, que tiene al padecimiento corporal como su motor. Según escribe de manera iluminadora Hernán mientras relata la presencia de Luy junto a la cama de terapia en la que morirá su abuelo, la «disociación entre la realidad y lo que Vicente vuelca en sus poemas [...] va cediendo paso a otras formas en el hospital» (2020: 31). En torno al hospital -en aquel entonces como visitante, en otros momentos como paciente-, se desarrolla un ciclo de emergencia de nuevas formas que puedan ya no enfrentarse a la realidad disociativamente, como simple negación, sino tejer vínculos inventivos con distintas piezas del territorio sobre el que operan.

Comparada con el «tú» y el «vosotros» de Caricatura, la aparición del «vos» y el «nosotros» en La vida en Córdoba, segundo libro de Luy, ya delata el cambio de régimen de la forma, en el que la monumentalidad material del volumen (una edición de autor de 22 x 31 centímetros y 1,7 kilos) no puede ser un detalle accesorio. La contundencia tangible del objeto converge con los avatares de una forma escrituraria que ya no consiente constreñir y empalizar a la vida hasta volverla muerte, sino que se afana por encauzarla con otra delicadeza, permitiendo que la materia adquiera presencia firme, excedentaria. La versificación irregular, la aparición de signos gráficos en lugar de algunas palabras (como en «Si yo disfrutara + sería - / mala onda.»; 2020: 47), los collages, las fotografías, las ilustraciones de Vaca Narvaja y el diseño de Hernán conducen un movimiento de expansión y multiplicación en el que los cuerpos que hacen posible la escritura ya no pueden quedar fuera de escena, sino que negocian su lugar con la palabra investigando diversas formas del aparecer. Es el comienzo de un trabajo intensivo de vaciamiento de la forma que no coincide con su eliminación, sino sólo con 
la eliminación de lo que hay en ella de exclusión, sujeción, jerarquización. El coloquialismo no es apenas un estilo, sino la experimentación con una forma que deje sonar el habla de la vida y es con ella que el padecimiento «propio» puede comenzar a adquirir nombres más precisos, entre los que se hallan palabras como «paranoico» o el anuncio «me tenté pero no me tiré» (2020: 37, 44).

De La vida en Córdoba de 1999 a Poesía moderna de 2001 y Aviones de 2002 (dos versiones de un mismo libro), se completa el movimiento de apertura hacia lo que Hernán llamó la multiplicación de las «voces» o la creación de «ventanas» (2020: 119), que es el desarrollo de una forma disponible a lo múltiple de la materia somática que lo hace posible. Precisamente vale la expresión de Hernán aquí porque su nombre designa un punto dentro de lo que llamamos el "complejo autoral" del que cuelga la poesía «de Luy»: ese obrar pende no sólo del cuerpo de Luy, sino de quienes como Hernán lo cuidan, que en una condición u otra empiezan a encontrar su lugar en los libros «de Luy» posteriores a Caricatura.

Aviones lo componen ya no apenas imágenes y decisiones gráficas de otros y otras, sino también cartas dirigidas a Luy, poemas y canciones ajenos a pedido, y fragmentos de los diarios de su abuelo y de su madre, sumergiendo la voz individual en un entramado colectivo. Ese complejo autoral lo componía - hasta poco antes de la aparición de la primera versión- el grupo Verbonautas (integrado junto al propio Hernán, Karina Cohen y Palo Pandolfo, entre otros), pero se extiende más allá en toda una red de sostenimiento recíproco, en el sentido de Joan Tronto y Berenice Fischer (1990). Detrás de la firma aparece todo el tejido material que sostiene la posibilidad de la escritura en nombre propio, y el dispositivo formal del montaje es aquello que permite su emergencia. Tanto Alejo Carbonell, en los paratextos de Escribir no es importante, que recopila poemas de toda la obra de Luy, como Hernán en La poesía está en ser uno hablan de «curaduría» (en Luy, 2020: 30; Hernán, 2020: 86) y es un término sugestivo para designar esa labor de puesta en forma de materiales diversos, siempre colectiva, en la que la organización cuida a la escritura y a aquellos y aquellas que subsisten en ella como su causa. El cuidado es también un asunto de emplazamiento (VV.AA., 2018: 5), una plástica del espacio en que las palabras cumplen una función organizativa ${ }^{5}$.

Aquel exceso de la energía respecto del carácter cerrado que pudiera adquirir la puesta en forma en la versión de Caricatura se nombra ahora en Aviones bajo la fórmula «hacer no es el hecho» (Luy, 2002: 5), de tal modo que la factura entre varios y varias sobresale siempre por encima de lo que se logre hacer aparecer en el efecto conclusivo de la obra. Los poemas se vuelven en Aviones más breves. Una poesía de ocasión, por su ligereza y soltura (que no implica en ningún caso trivialidad: «es ligero el dolor/ ligera la palabra/ ligera la risa»; 2002: 77), pero también por su manifiesta condición «ocasionada», su renuncia a darse por autocreada, autónoma: es un hacer que exhibe su causalidad plural —el tiempo presente que la (con)mueve y la actividad mancomunada- como su sustancia íntima.

En el cuerpo de Aviones, una carta de Silvino Costa 6 introduce de manera frontal la «depresión» de Luy y discute el ascendente de las «pastillitas» 
respecto de otras terapéuticas posibles: el acompañamiento de Angélica, las palabras de aliento del propio Costa, "amor y amistad» (Luy, 2002: 1114). El orden dentro del libro la hace preceder varias páginas, como respuesta anticipada, el informe psiquiátrico manuscrito de una terapeuta a la que el abuelo Larrea había remitido a Luy —que recomienda la continua vigilancia de «especialistas»-, la orden de alta del Hospital Borda a su amigo Guillermo Crook y su propia designación de «una tarde PROZAC» (2002: 26, 76, 103). ¿La escritura es parte de esos intercambios de amor y amistad que sacan de la depresión, negocia las altas y bajas, o modula los altibajos anímicos farmacorregulados? El acto de lectura puede hacer lugar a decisiones en uno u otro sentido, o también dejar en ese sitio alguna indecisión; pero lo que el complejo escriturario en Aviones impone sin duda es situar la escritura «firmable» en esa orquesta de materiales diversos, las «materialidades del cuidado» (VV.AA., 2018) ${ }^{7}$, como intervención minuta sobre esa red, donde «lo que está atrás es el dolor» (Luy, 2002: 132) y ese atrás viene permanentemente hacia adelante, no deja de emerger, como un efecto de la misma forma. Allí donde podría guarecer su propia soberanía poética, el poder de la lengua, la forma que opera en Luy se afana por crear huecos que hagan aparecer lo otro:

\author{
No es la lengua \\ ni la lengua que se esconde \\ en el pantano de la razón \\ no es la voz \\ No es la forma \\ en que los silencios \\ hacen bailar las palabras. \\ Es la hendija \\ donde el poema \\ es rehén (2002: 17).
}

Esa cautividad voluntaria del poema, que se rehúsa a tomar sus silencios como formas de la autoridad sobre las voces que suenan desde fuera, es también una forma ¿literaria? posible, un destino del poema contra su autonomía y la dominación sobre el territorio que habita, y en favor de la hendija a través de la cual la voz se multiplica en muchas, se oyen pulsos somáticos que ya no son voces y ya no hay escondites.

No le pidan peras a Cuper, de 2003, sin perder la ligereza del lenguaje, complejiza su sintaxis. La depuración de la forma sigue fabricando aberturas, al punto de que «mi centro es hueco./ Visitado por un montón de esquizos» (Luy, 2020: 75); pero el vaciamiento no conduce forzosamente a la simplificación, sino que puede espiralarse y recargarse:

Forma.

Reforma.

Contrarreforma.

El cielo no es lo que parece.

Y no es cuestión de forma;

o vos me formás

o yo te formo (2020: 76). 
De manera frontal, en la forma se dirimen cuestiones de poder, de unos o unas sobre otros u otras, sean sujetos singulares o instituciones poderosas como la Iglesia. El trabajo, formal, sobre la forma, indecidible entre el humor y la ofuscación, decide en su regodeo verbal aliterativo el problema político del aparecer y el parecer, que no es una simple «cuestión de forma». De acuerdo con Hernán, «Vicente escribió la mayoría del libro con la televisión prendida y los diarios abiertos sobre la mesa», y esa materia -más evidente en otros poemas del libro- potencia el filo político de la pregunta por la aparición y la apariencia, exacerbada cuando el diario Página/12 se niega a publicar un anuncio del libro y Luy decide denunciarlo en afiches callejeros (2020: 72). En la segunda estrofa de «Forma./ Reforma» hay un anuncio que desata suspenso, casi una amenaza, desde o hacia el cielo (allí desde donde, recordémoslo, cuelgan Luy y su poema); pero la incertidumbre sobre el éxito en la búsqueda de la forma verbal necesaria para la vida no lleva a la aceptación del fracaso: « ¿Tus palabras no atraviesan las paredes?/ Modificá tus palabras» (2020: 86).

La sexualidad de Gabriela Sabatini, de 2006, antologa los libros anteriores y añade una veintena de poemas nuevos, incluido este poema programático:

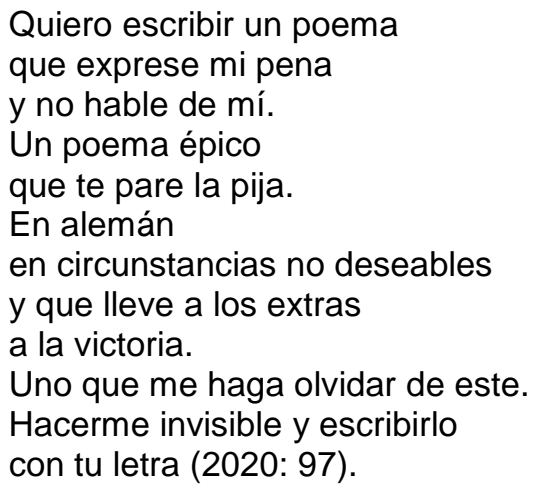

Esa distancia, típica de los manifiestos, en la que la obra queda dispensada al futuro respecto del presente de lo efectivamente escrito, funciona como un nuevo recurso para dejar entrar los márgenes dentro de la página: los efectos de la obra sobre quienes lean, «los extras», la letra ajena. El uso del nombre de la tenista en el título del libro, más allá de las consecuencias publicitarias inmediatas, acaba participando de la misma investigación sobre los bordes. El título queda aislado de los poemas en el interior del volumen, cobijado apenas por una nota inicial: «En este libro no se hacen referencias a la sexualidad de la Srta. Sabatini. El título es una metáfora. ¿Una metáfora de qué?». Como han señalado varios lectores, Luy es todo menos metafórico, al menos en cualquier sentido tradicional del concepto de metáfora. Doblemente críptica entonces como respuesta, la advertencia mantiene en el horizonte el carácter táctico de los umbrales, la manipulación indisimulada de las aberturas como procedimiento formal.

Las operaciones de montaje siguen en el centro de la escritura de Luy en ¡Qué campo ni campo!, de 2008. Pero ya no es la simple yuxtaposición, sino que el recurso a la transparencia, enunciada en el poema del libro anterior que citábamos, renueva la pregunta por el arriba y el abajo, como en la página a continuación: 


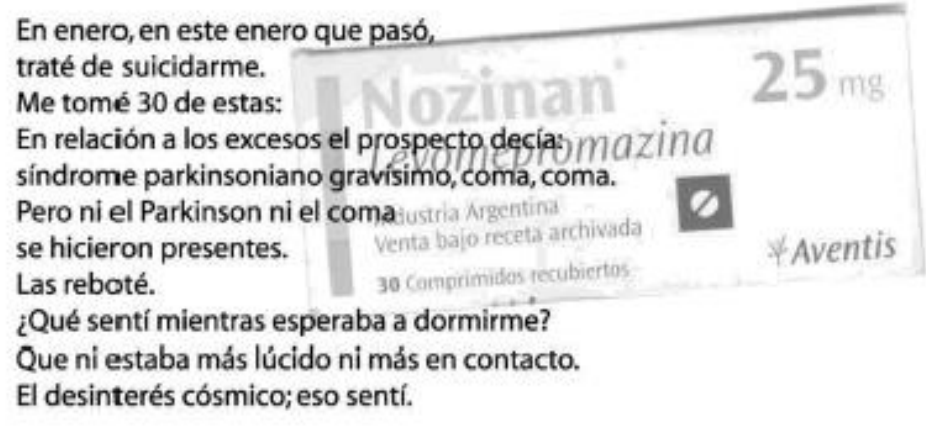

Poema de ¡Qué campo ni campo! (Luy, 2008: 12).

Imposible decidir cuál de los dos elementos de la página es el que se adelgaza para dejar aparecer al otro, porque las decisiones gráficas llegan a la lectura como simultaneidad espacial. Para quien lee, ambos se transparentan a la vez, haciendo el lugar común en que sus materialidades coinciden. La invitación verbal a la fotografía («30 de estas:») entra en bucle causal: la facticidad material contingente en la que la combinación del cuerpo de Luy y el remedio fotografiado no conllevaron el coma es lo que hace posible la escritura, que a su vez hace lugar a la imagen fotográfica de la droga. En la referencia cruzada, el padecimiento es lo que aparece como justificación de la incrustación material de la foto: la materia somática del dolor suscita esa oquedad de la forma, como llamado al cuidado. Y es que ese movimiento en que la forma ya no funciona como opacidad o cerrazón sino como su inversión risueña gobierna el poemario: «Me porto como cualquiera/ tapando el dolor con bronca/ y otras cosas:/ hoy con goles, pastillas, vodka/ y hasta con la birome» (2008: 39). Si la escritura viene a tapar algo, ha fracasado; pero el plan parece otro: «mostrar el proceso, dejar constancia» (Hernán, 2020: 196).

Plan de operaciones y La única manera de vivir a gusto es estando poseído, editado póstumamente por Hernán, recoge por un lado el libro en el que trabajaba Luy hasta su suicidio (Plan), y por otro los demás textos inéditos de esos años (La única). El prólogo de Hernán los coloca «a los hombros del Prozac», su "combustible», y entre las internaciones en hospitales y neuropsiquiátricos de Córdoba y Buenos Aires (en Luy, 2012: 9-10; Hernán, 2020: 176). Difícil saber si Luy habría instalado ese marco de una manera tan explícita como la elegida por Hernán, pero, como venimos viendo, la escritura de Luy nunca es un acto de autoría personal que deje fuera el trabajo múltiple de los y las demás, de tal modo que esas inscripciones del editor cuentan tanto como cualquier otra entre las condiciones intrínsecas de ese obrar. Los poemas-crónica ponen en primer plano ese trabajo a varias manos:

Me duermo. Ya son la 3 y mañana tengo que ir a trabajar. [...]

Igual (3era. vez que meto igual en el texto) lo tomo

como algo provisorio cuasi terapéutico. [...]

Con mi carnet de discapacitado puedo viajar a todos lados.

Semi cama; es incómodo, pero se banca,

Voy a ver a los Flopas, y a la Ruiz.

Y el fin de semana, a trabajar a full con Hernán (2012: 17). 
El poema relata su propia producción, distribuida entre las disposiciones corporales que se inscriben poética y jurídicamente y la constitución de ese trabajo colectivo, en este caso, «con Hernán». La vuelta de la escritura sobre sí misma, en el paréntesis, nunca opera borrando, sino acumulando; los niveles de la escritura se agregan como las demás materialidades. En una línea convergente, la entrevista, exceso pretendidamente «informe» en todo archivo literario, invade la obra literaria bajo la modalidad, inventada en poemarios anteriores, de una conversación entre poeta («V.») y discípulo («D.»), con marcas gráficas de diálogo. Hernán refuerza la continuidad entre la entrevista genuina y la «ficticia» incorporando en el libro una entrevista de Juan Manuel Daza a Luy. Lejos de la hipótesis de lo informe como desaparición de la forma, la variación entre una y otra coloca en primer plano la contingencia de la puesta en forma como ejercicio práctico sobre los materiales de la vida.

Así como en algunos casos los pliegos oponen textos a fotografías, dibujos y collages, en otras ocasiones enfrentan poemas pareados que se dejan leer en tándem:

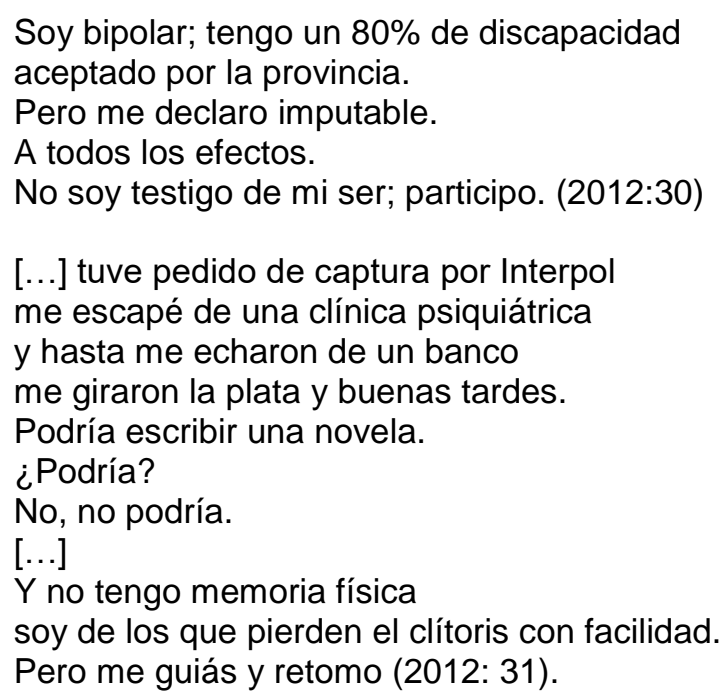

En estos dos poemas pareados, la poesía aparece como aquel avatar de la forma consistente con la discapacidad, aquello que se puede cuando no se puede tener aquel «dominio de sí» exigido por la psiquiatrización y al mismo tiempo por la forma novela. Es un escribir que se deja guiar, que retoma la guía del otro o la otra, sin borrar al sujeto singular sino intrincándolo con otros y otras, en el mismo complejo autoral de los libros previos, pero que entra ahora en nuevas tramas explicativas. Como dirá otro de los poemas del libro, «Nada de lo que me pega me desvía./ Todo lo que me pega me conduce.-» (2012: 60); esa conducción o causación múltiple es la materia que hace posible el poema, pero también la fuerza que da en él forma (no hay ya modo de distribuir forma y materia sobre la oposición entre sujetos y objetos, como quiso la fenomenología clásica de cierto Husserl; Gelman Constantin, 2019).

El enredo del problema de la causación con la materia somática, la materia sonora y la operación poética de puesta en forma, entre el padecimiento y el cuidado, asedia todo el poemario. 


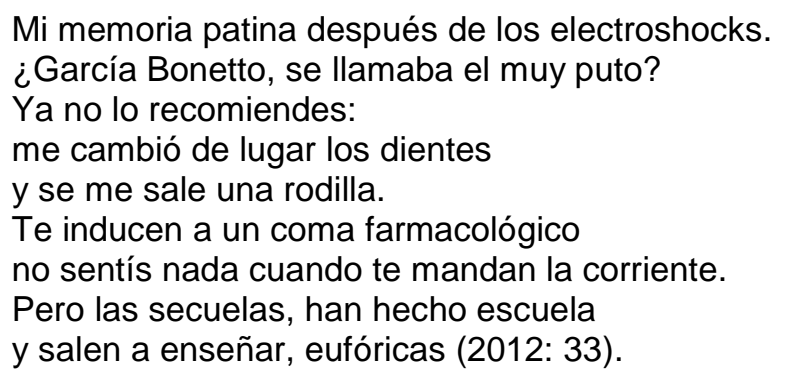

Si la forma poética es un efecto del cuerpo discapacitado, la poesía está en la capacidad de desviar delicadamente la causación, en el magnífico calambur: de las secuelas, escuela. Después de los electroshocks, el cuerpo hace escuela, pese a lo que se olvida y por ello, contra la voluntad médica, en esa escritura que lo deja aparecer, salir, enseñarse.

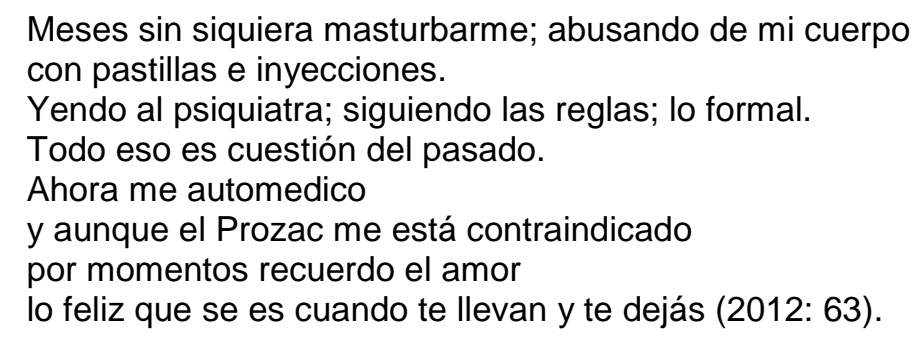

Contra «lo formal», Plan de operaciones sigue proponiendo otras formas, que lejos de cualquier imposición sobre los materiales sobre los que actúa, son un "dejarse llevar», el don de líneas para alguna "autogestión» alternativa de la materia, cercana a la automedicación, pero no forzosamente tan riesgosa (o por lo menos no en el mismo sentido), toda vez que suponen el sujeto colectivo, amoroso y heterogéneo de quienes «te llevan».

\section{En forma de (in)conclusiones}

El trayecto cronológico por los libros de Luy no quiso componer un arco evolutivo, como si la reinscripción de la poesía entre la materia viviente sobre la que opera (o podría operar) obligara a regresar a los arcos biográficos novelescos que fabricó la crítica literaria vitalista. La narrativa trazada en ese recorrido es la de esta propia investigación, a medida que indaga aquellos vínculos, formales y materiales, entre vida y obra que suscita la importancia del cuidado en la constitución de la obra «de Luy».

Avanzando sobre investigaciones previas (Gelman Constantin, 2019), podemos decir - a partir de la lectura de Luy, Hernán y esa serie abierta de nombres que sostienen su obra, ¿desde arriba, desde adelante?- que es necesaria una teoría posautónoma de la forma que la conciba en términos de un proceso técnico de modificación de la materia o los materiales sobre los que opera. La forma consistiría, pues, a nuestros efectos, en aquello que los procedimientos escriturarios hacen sobre la materia que trabajan (jo tratan!) y a la que convierten, al menos en parte, en su contenido; la forma no existe por sí sola en ninguna parte que no sean las prácticas que integra o los objetos que esas prácticas dejan detrás, ni como contenido preexistente en un sujeto, ni como trascendencia 
transhistórica de ningún tipo, pero es susceptible de entrar en procesos de replicación, con todas las ínfimas e impredecibles diferencias que eso supone en el encuentro con cada nueva materia.

Si es una teoría posautónoma es porque los juicios que quepa hacer sobre esas formas son del orden de la(s) eficacia(s), la axiología ético-política y esa misma replicabilidad; son formas que pertenecen enteramente al orden de la praxis social y sus atributos no dependen de la distinción respecto de algún orden de la realidad que dejan fuera, detrás o debajo, sino de su capacidad de inmiscuirse donde puedan ser útiles. Su(s) utilidad(es) o eficacia(s) no son neutras o ilimitadas, pero sí imposibles de predeterminar de antemano (algo de eso nos enseñaba hace años la teoría de la refuncionalización).

Una teoría posautónoma de la forma, con Luy, Hernán y los y las demás, nos empuja a perseguir aquellos procesos de puesta en forma que supongan la apertura del lugar vital en que los materiales sobre los que opera y que hacen posible su subsistencia como forma no resulten acallados, sino que sean perceptibles en escena: formas que no dejen atrás o reifiquen aquellos padecimientos, alegrías y cuidados que son sus condiciones de existencia, en su basta y vasta materialidad. Formas que puedan ofrecerles nuevas fuerzas y nuevas conexiones.

Hablar desde aquí de formas y materias de cuidado, es hacer aparecer a la escritura en tramas heterogéneas de sostenimiento de la vida, incluso lamentablemente- de aquellas que acaben en el suicidio. Es entender el desaprendizaje de la autonomía como una vía necesaria para que vuelvan a escena condiciones de posibilidad y al mismo tiempo se pueda operar crítica y transformadoramente sobre ellas, a través de las prácticas mismas de la escritura, el montaje, la lectura, en la perceptible materialidad de sus procesos de puesta en forma.

\section{Bibliografía citada}

ADORNO, T. W. (1962): «El artista como lugarteniente» en Notas sobre literatura. Sacristán, M. (trad.), Barcelona: Ariel, 123-144.

Adorno, T. W. (2014): Teoría estética [1970]. Navarro Pérez, J. (trad.), Madrid: Akal.

Bogado, F. (2018): «Crítica e imagen: lectura comparada de Aquí América Latina de Josefina Ludmer y Plan de operaciones de Vicente Luy», Perífrasis, vol. IX, 17, 113-131.

Bogado, F. (2019): «Poesía parenética y guerra: análisis de seis poemas de Vicente Luy», Cuadernos LíRICO, vol. XX, 1-12.

Brizuela, N. (2014): Depois da fotografia. Nougué, C. (trad.), Rio de Janeiro: Rocco.

Butler, J. (2010): «Vida precaria, vida digna de duelo» en Marcos de guerra. Moreno Carrillo, B. (trad.), México D. F.: Paidós, 13-55.

DOSSE, f. (1997): history of Structuralism. Glassman, D. (trad.), Minneapolis: University of Minnesota Press.

Eichenbaum, B. (2004): «La teoría del "método formal"» en Todorov, T. (comp.), Teoría de la literatura de los formalistas rusos, Buenos Aires, Siglo XXI, 21-54. Nethol, A. (trad). 
GELMAN CONSTANTIN, F. (2019): «Otro tiempo de vida. La puesta en forma como encrucijada de la teoría», Badebec, vol. VIII, 16, 1-25.

GRINBERG, M. (2013): «Plegaria para un niño sufrido», Cítrica, 4.12, s/p.

groys, b. (2014): «Introducción: Poética vs. Estética» en Volverse público. CortesRocca, P. (trad.), Buenos Aires: Caja Negra, 9-19.

groys, b. (2020): «Bajo la mirada de la teoría» en Arte en flujo. Cortes-Rocca, P. (trad.), Buenos Aires: Caja Negra, 33-54.

Hernán (2020): La poesía está en ser uno. Los libros de Vicente Luy, Rosario: Beatriz Viterbo.

kohan, m. (2013): «Sobre la Posautonomía», Landa, 1.2. 309-319.

kohan, m. (2020): «César Aira, Ricardo Piglia: notas para un piano solo», ponencia

en las XXXII Jornadas de Investigación del Instituto de Literatura Hispanoamericana. Buenos Aires: ILH, Facultad de Filosofía y Letras (UBA). 9 al 13 de marzo de 2020.

LACAN, J. (2004): «Séminaire 14. La logique du phantasme» en Melman, C (ed.), Les Séminaires, Paris: AFI, 6269-6738.

Ludmer, J. (2010): Aquí América Latina, Buenos Aires: Eterna Cadencia.

Luy, V. (2002): Aviones, Córdoba: ed. del autor.

Luy, V. (2008): ¡Qué campo ni campo!, Córdoba: llantodemudo.

Luy, V. (2012): Plan de operaciones y La única manera de vivir a gusto es estando poseído. Hernán (ed.), Buenos Aires: crackUp.

Luy, V. (2018): Caricatura de un enfermo de amor [1991], Buenos Aires: Años Luz. Luy, V. (2020): Escribir no es importante. Carbonell, A. (ed.), Córdoba: Caballo Negro.

pauls, A. (2014): «El arte de vivir en arte» en Guerriero, L. (ed.), Temas lentos, Santiago: Diego Portales, 166-184.

RIVERA CUSICANQUI, S. (2015): Sociología de la imagen, Buenos Aires: Tinta Limón.

SY, A. (2016): «Una aproximación a la diversidad de perspectivas en torno a la atención del sufrimiento psíquico desde el arte», Revista de salud pública, 20.2. 22-39.

Tronto, J. y Fisher, B. (1990): «Toward a Feminist Theory of Caring» en Abel, E. K y Nelson, M. K. (eds.), Circles of Care, Albany: SUNY, 35-62.

VALLEJO, C. (2013): Obras completas, Buenos Aires: Losada.

VV.AA. (2018): materialities of Care. Buse, C.; Martin, D. y Nettleton, S. (eds.), Oxford: Blackwell.

\footnotetext{
${ }^{1}$ El desarrollo del ciclo en el interior del hospital no estuvo exento de tensiones, que Hernán ubica entre «la humanidad y la mezquindad de los médicos» que «jugaban pulseadas bestiales dentro del Servicio» (2020: 213). Como explica Anahí Sy (2016), a diferencia de las actividades del Frente de Artistas del Borda o la Radio La Colifata, que funcionan de manera asamblearia reuniendo a internos y externos, el Centro Cultural siempre estuvo bajo la dirección de un médico, con las consecuentes dinámicas de poder, y con efectos directos sobre la concepción del sentido y la función de la palabra o el arte en su interior.

2 La conexión de los argumentos de Cusicanqui y Lacan alrededor de la cuestión aristotélica de la relación entre el noein [pensar], el phánetai [(a)paracer, hacer(se) presente] y los eikones [imágenes] —que explica algunos de los términos que se repiten a lo largo del artículo- no puede pasar aquí de un hilván inicial. Someramente, se los puede reunir como reescrituras del dictum de Aristóteles de que «nunca intelige el alma

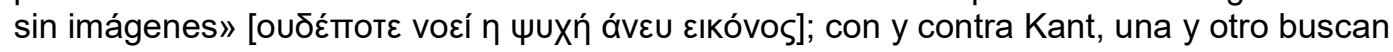
modos de hacer con esa constatación que no consientan su largo efecto civilizatorio de sanción de una jerarquía de seres según el mejor, peor o nulo ejercicio de cada facultad del alma que se les atribuya. En un caso, la objeción de esas jerarquías se inscribe en el ciclo de levantamientos descolonizadores, anticapitalistas y antiestatalistas andinos del que participa Cusicanqui; en el otro, hay que reconocer el eco de la disidencia de las (¿post-?) humanidades al nuevo papel de las facultades empresariales en la gestión de la
} 
cosa pública que pone a Lacan de camino — por mucho que lo incomode a él mismo- de mayo del 68 y «la imaginación al poder» (sobre el enlace de estas disputas entre facultades con las revueltas obrero-estudiantiles, la referencia es el volumen de François Dosse, 1997). Una argumentación más detallada de estas sugerencias preliminares sería la ocasión de otro artículo.

Por lo que concierne a la relación entre las imágenes a secas y las imágenes verbales, el deslizamiento no es — desde ya y por lo menos desde aquellos escritos fundacionales de la teoría literaria que circundan las fogatas de las revoluciones rusas - evidente por sí mismo. Pero la obra de una y otro autor ofrecen suficientes elementos para pensar sus vínculos de una manera no automáticamente disyuntiva, y que oportunamente conecta con el problema de la causación en el que está comprometido este artículo. En Cusicanqui, las prácticas de conocimiento descolonizadoras -admitido el acceso diferencial a la escritura que implicó el sistema colonial- incluyen la intensificación de los efectos de las imágenes (visuales, táctiles, olfativas) sobre una imaginación colectiva ch'ixi que incluye los lenguajes verbales escrito y oral, y que solo puede adquirir cohesión en sus entrelazamientos figurales multívocos. En Lacan, la fascinación imaginaria entendida en términos de prensión visual de los sujetos provoca la constitución del registro de lo imaginario, que atraviesa todas las formas de significación y que explica algunas de sus tropologías.

1 Si Pauls rastreaba en el «arte de vivir en arte» un «yo que hace» (2014: 183-184) como «pura cámara de resonancia» que excedía así el egotismo narcisista para inscribir una forma de vida colectivizable, como veremos, la lectura de Luy con Hernán y el plural autoral enredado en los libros de Luy nos lleva a una primera persona del plural incremental, un nosotres inclusivo.

${ }^{1}$ Más obviamente en un artículo posterior (2019), que parece saldar lo que quedaba entre signos de pregunta en el texto previo.

1 ¿Por qué seguir hablando de la obra «de Luy» en el marco de ese complejo autoral en red que la hace posible y seguir leyéndola de un modo que individualice y separe aquellas publicaciones presididas por su firma? La objeción perspicaz planteada por una de las primeras personas en leer este artículo es enteramente legítima y amerita atención; quepa apuntar aquí además mi gratitud a ese lector o lectora.

Una primera respuesta sería que la relación entre la red de cuidado y el obrar no es biunívoca, y los modos en que la operación técnica de la forma hace aparecer a esa red no son homogéneos entre distintas escrituras. Es decir, por un lado, las obras que firman con su propio nombre esos distintos autores y autoras que a su vez pueden advertirse «detrás» de la obra «de Luy» no dependen forzosamente de la misma red de cuidado que sostiene la obra «de Luy»; y esto no porque las y los cuidadores no sean a su vez cuidados, sino porque eso no necesariamente queda en las mismas manos. Y, por otro lado, nada garantiza que diferentes obras hechas posibles por una misma red hagan presente del mismo modo esa condición; precisamente en esa divergencia reside la singularidad concreta de toda forma, al mismo tiempo que ello expresa que una misma causación no tiene efectos idénticos en todas partes. En tal sentido, sostener la referencia a la obra «de Luy» como foco de este artículo implica identificar aquellos textos y aquellas «escenas» (para seguir a Pauls) que vienen a nuestras manos adheridos al nombre de Luy como un insumo especialmente apto para las reflexiones desplegadas aquí.

${ }^{1}$ Se trata de un estafador portugués al que Luy conoce durante su breve prisión en Suiza, según explica Hernán (2020: 95). El recibo de la fianza de Luy está también entre los papeles insertos en el libro.

1 El concepto de «materialidades del cuidado» proviene del trabajo de los llamados «nuevos materialismos» en las humanidades y las ciencias, que subrayan la agentividad de objetos inanimados en su ensamblaje con las demás entidades. Por lo que respecta a la posición de la escritura en ese giro, de lo que se trata no es de desplazar u olvidar el lugar de la lengua, sino de que ella ceda la posición soberana de privilegio de la que pudo gozar en el estructuralismo o postestructuralismo, para entrar en montajes complejos e indisciplinados con materiales no verbales, como en los propios «montajes de salud» (VV.AA., 2018: 1). 